\title{
Organic Wastes Degradation by U.V. Radiation
}

\author{
Anindita Bhattacharya ${ }^{1}$, Alka Tangri ${ }^{2}$ \\ ${ }^{1}$ Department of Chemistry, Christ Church College, Kanpur - 208001 \\ ${ }^{2}$ Department of Chemistry, Brahmanand College, Kanpur - 208001
}

\begin{abstract}
Indian industries use water in a very high quantity as compared to other countries' water usage. Inefficient water use by industries in India creates a lot of problems. This quantity could be reduced to a minimal by recycling the water after sufficient treatment. This work aims at sufficient in-situ treatment of wastewater and recycling of water for low-grade applications in the industry. Complete destruction of the contaminant is possible using inexhaustible, free source of energy from sunlight thus consuming very less primary energy for its operation. Photocatalytic experiments were carried out using laboratory photo reactor for degradation of phenol wastewater. The experiments were carried out with $0.2 \mathrm{~g} / \mathrm{l}$ of TiO2 catalyst for different concentration of phenol wastewater ranging from 100, 300 and $500 \mathrm{ppm}$. It is found that complete degradation of phenol is possible in a reasonable time (i.e. less than $5 \mathrm{hrs}$ ) when concentration of phenol is $\leq 100 \mathrm{ppm}$.
\end{abstract}

Keywords: wastewater, phenol, solar, photocatalytic treatment, potential

\section{INTRODUCTION}

Every community produces both liquid and solid wastes. The wastewater is essentially the water supply of the community after it has been fouled by a variety of uses. From the stand point of sources of generation, wastewater may be defined as a combination of the liquid or water carried wastes removed from residences, institutions, commercial and industrial establishments, together with such ground water, surface water \& storm water as may be present. Industrial wastes containing dissolved organic compounds have posed and continue to pose serious pollution problems. Although most of the organic compounds found in wastewater can be treated readily, the number of such compounds that are not amenable to treatment or that are only slightly amenable to treatment with the conventional processes presently used is increasing. Moreover, in many cases, little or no information is available on the long term environmental effects caused by the presence of these compounds. To understand the effect more clearly, it is anticipated that more emphasis shall be placed on advanced treatment for the removal of specific contamination.

Since the need for producing "organic free" water has become extremely important, especially in the industrialized nations, continuous efforts are being made to develop methods for purifying water either by removing these impurities or by converting them into harmless products.

A number of methods are currently available to destroy such compounds. In which, the photo catalysis is an emerging water treatment technology that destroys organic contaminates under ambient pressure and at a non-elevated temperature. It is a process is which the illumination of an oxide semiconductor produces photoexcited electrons and holes. These can migrate to the oxide surface and participate in half-cell reactions that are part of a closed, catalytic cycle. In the aqueous phase, the illuminated surface is widely regarded as a producer of hydroxyl radicals (e.g. $\left.\mathrm{H}^{+}+\mathrm{OH}^{-} * \mathrm{OH}\right), \&$ these other highly oxidizing initial products of \& indirect photochemistry go on to attack oxidizable contaminants i.e. the photocatalysis can mineralize the organic contaminants into simple mineral acid, carbon dioxide \& water.

Hence the details of study of effect of various oxidizing agents such as $\mathrm{TiO}_{2}, \mathrm{H}_{2} \mathrm{O}_{2}, \mathrm{O}_{3}$ etc. during the process of photocatalytic degradation to complete removal of organic waste to batch process as well as continuous process has been undertaken in this study. The use of photocatalytic oxidation is the process of absorption of photons acting as a catalyst in producing reactive radicals. This can oxidize organic compounds. Organic compounds are decomposed to from carbon dioxide, water and mineral acids, as final product effect of temperature on this process is very small; therefore this process is referred as a cold process.

\section{MATERIALS AND METHODS}

Phenol solution obtained from Merck Chemical Co., was prepared in $100 \mathrm{mg} \mathrm{L}-1$ concentrations The concentration of phenol was measured at $500 \mathrm{~nm}$ by a Shimatsu spectrophotometer. $\mathrm{TiO} 2$ was used mostly anatase and had a BET surface area of $50 \mathrm{~m} 2 \mathrm{~g}-1$ and an average particle diameter of $30 \mathrm{~nm}$. Adjustment in samples was done by using $0.1 \mathrm{~N}$ $\mathrm{HCl}$ acids (Merck, 37\%) and $0.1 \mathrm{~N} \mathrm{NH4OH}$ (Merck $25 \%$ ). A low pressure UV lamp, $0.8 \mathrm{~m}$ in length was installed $10 \mathrm{~cm}$ above the samples surface and the light intensity were $0.9 \mathrm{~J} \mathrm{~s}-1 \mathrm{~m}-2$ measured by a Radiometer 
at 300 to $400 \mathrm{~nm}$ (Hagner EC1-UVA). All analysis were done according to the standard methods (14).

In this research, the photochemical cell consisted of five $250 \mathrm{ml}$ beaker and 5 magnetic stirrers that used for stirring the samples. The temperature of reactors was controlled at $20^{\circ} \mathrm{C}$. In the first phase, the beakers were filled with $200 \mathrm{ml}$ of phenol solution (100 mg L-1) and in separate stages were contacted with UV $\mathrm{TiO} 2$ and combination of $\mathrm{UV} / \mathrm{TiO} 2$. Also the effects of various parameters include contact time $(1,3,5$, and 9 h), $\mathrm{pH}$ (3, 7 and 11) and amount of $\mathrm{TiO} 2$ (0.5 and 1.0 gr L-1) in the removal efficiency of phenol were investigated. The polished aluminium was used a reflective material to protect the samples in the absence of radiation. The samples were withdrawn from the beakers with the syringe $(10 \mathrm{ml})$ before and after the photochemical reaction and the residual phenol was measured. Before phenol measurement, the samples containing $\mathrm{TiO} 2$ were centrifuged at $5000 \mathrm{rpm}$ for 10 min, and then the upper liquid layer were sucked with a glass syringe and filtered. Then concentration of phenol in the prepared samples was measured. All experiments were conducted at lab temperature (nominally $20^{\circ} \mathrm{C}$ ).

\section{RESULTS}

The results from examinations in $\mathrm{pH}=3,7$ and 11 as the function of exposed time in the studied .It is found that phenol degradation efficiency is affected by $\mathrm{TiO} 2$ concentration, UV irradiation and $\mathrm{pH}$ of the solution. Also the effect of time variation on removal phenol at different $\mathrm{pH}$ values is shown in The results show that degradation yield in a $9 \mathrm{~h}$ period with $\mathrm{pH}=3$, 7 and 11 has been 59\%, 52\% and $83 \%$, respectively.

\section{DISCUSSION}

The photocatalytic degradation of various toxic organic compounds has been proposed as a viable process to detoxify aquatic solutions. Irradiating pulverulent semi-conductors like $\mathrm{TiO} 2$ in suspension or fixed to various supports in aqueous solutions containing organic pollutants, creates a redox environment able to destroy these pollutants. Solar photocatalytic mineralization of organic water pollutants has a strong potential in the industrial destruction of toxic organics in water as this has been widely demonstrated in recent years, and the applications and target compounds are numerous. Process for phenol degradation is compatible with the environmental. In conclusion, the reaction rates of photocatalytic degradation of phenol were influenced by $\mathrm{pH}$ value. Photodegradation can be an alternative treatment method for those contaminants resistant to conventional methods. Photodegradation can be used for complete mineralization of phenol. Since $\mathrm{TiO} 2$ that was used in this study, is a recoverable photocatalyst, $\mathrm{UV} / \mathrm{TiO} 2$ process for phenol degradation is compatible with the environmental.

Table: 4.2.1. Calibration Curve data

\begin{tabular}{|c|c|}
\hline $\boldsymbol{\mu g} / \mathbf{m l}$ of phenol & Absorbance \\
\hline 0 & 0 \\
\hline 10 & 0.020 \\
\hline 30 & 0.052 \\
\hline 50 & 0.082 \\
\hline 70 & 0.112 \\
\hline 100 & 0.151 \\
\hline
\end{tabular}

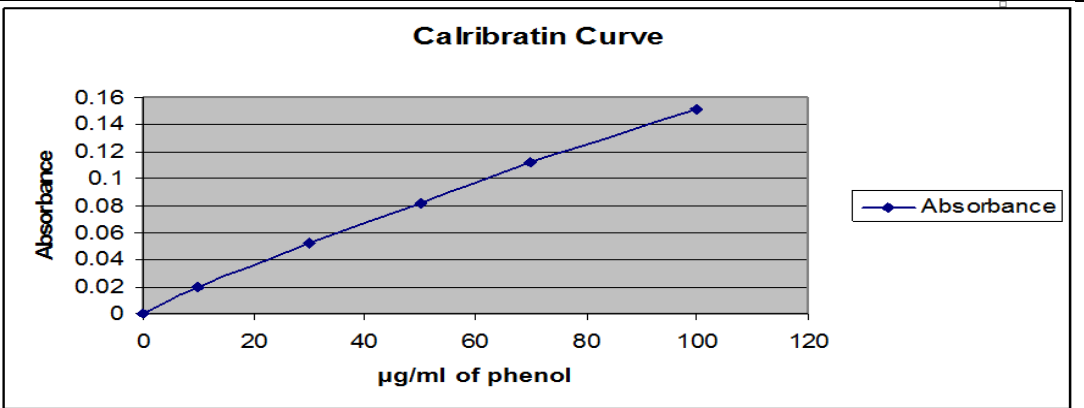

TTable: 4.2.2 Percentage degradation of phenol with time (100 ppm of phenol is solution)

\begin{tabular}{|c|c|c|}
\hline S.No. & Time (Hours) & Percentage degradation \\
\hline 1 & 0.0 & 0 \\
\hline 2 & 0.5 & 6.20 \\
\hline 3 & 1.0 & 8.00 \\
\hline 4 & 1.5 & 12.00 \\
\hline 5 & 2 & 12.8 \\
\hline
\end{tabular}




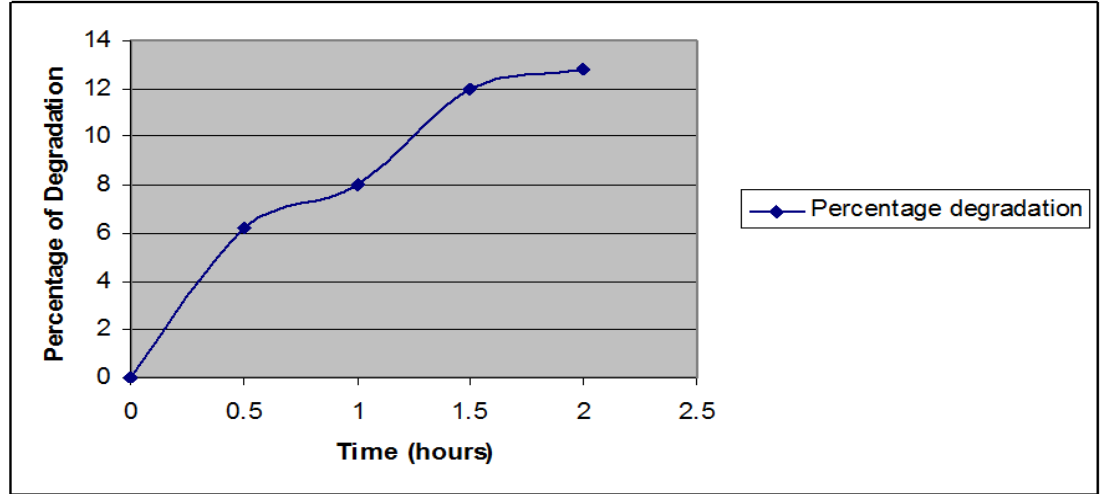

Fig. 4.2.2: Percentage degradation of phenol (100 ppm) Vs time (hours)

Table: 4.2.3 Percentage degradation of phenol with time ( $300 \mathrm{ppm}$ of phenol is solution)

\begin{tabular}{|c|c|c|}
\hline S.No. & Time (Hours) & Percentage degradation \\
\hline 1 & 0.0 & 0 \\
\hline 2 & 0.5 & 2.9 \\
\hline 3 & 1.0 & 4 \\
\hline 4 & 1.5 & 4.2 \\
\hline 5 & 2 & 4.3 \\
\hline
\end{tabular}

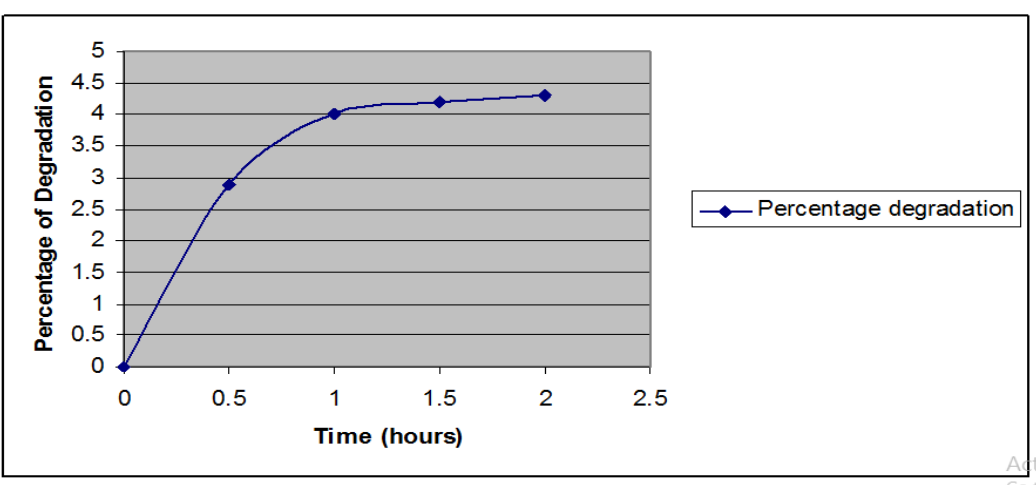

Table: 4.2.4 Percentage degradation of phenol with time (500 ppm of phenol is solution)

\begin{tabular}{|c|c|c|}
\hline S.No. & Time (Hours) & Percentage degradation \\
\hline 1 & 0.0 & 0 \\
\hline 2 & 0.5 & 2.5 \\
\hline 3 & 1.0 & 2.8 \\
\hline 4 & 1.5 & 3.9 \\
\hline 5 & 2 & 4.0 \\
\hline
\end{tabular}

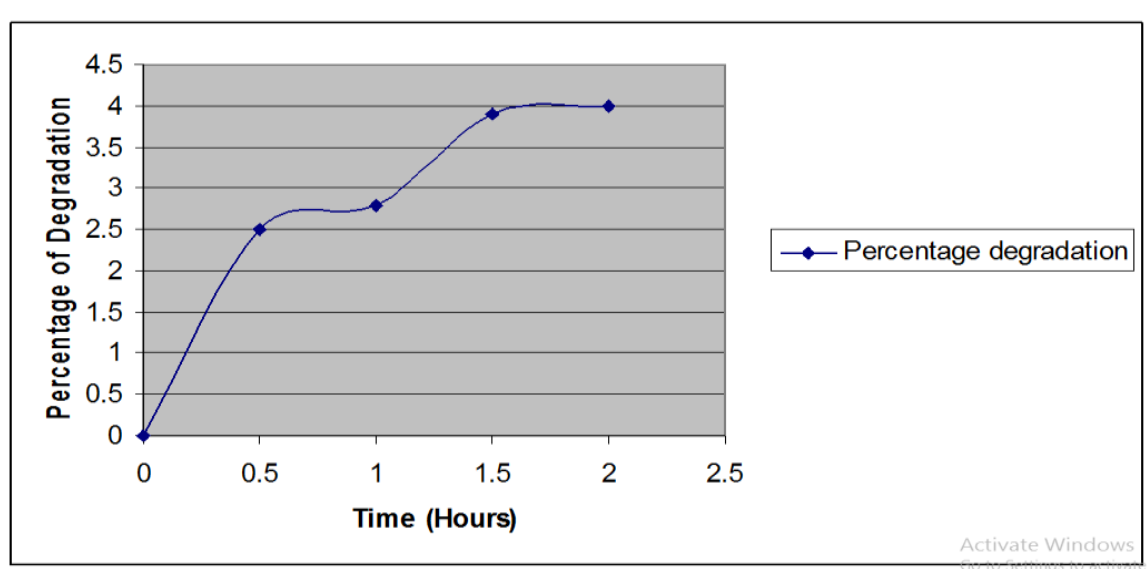




\section{CONCLUSION}

The extent of degradation increases with time, but rate of degradation is higher in the initial periods and later on there is a decrease in the same. The extent of degradation deceases with increase in the concentration of phenol.

\section{REFERENCES}

[1]. D.K. Singh \& Bhavana Srivastava, "Removal of phenol pollutants from aqueous solutions using various adsorbents", J. of scientific and industrial research, Vol. 61, pp. 208-218, 2002

[2]. C.P. Das \& L.N. Patnaik, "Removal of phenol by Industrial solid waste", Pract. Periodical of Haz, Toxic, and radioactive waste management. Vo. 9, pp. 135-140, 2005.

[3]. S. Bhattacharya \& C. Preston Clements, "Solar detoxification of waste water", Indian Chem. Engr. Section B. Vol 41, pp. 150157, 1999.

[4]. B. Neppolian, M.V. Shankar \& V. Murugesan."Semiconductor assisted photodegradation to textile dye", J. of scientific and industrial research, Vol. 61, pp. 224-230, 2002.

[5]. Amol A. Kulkarni, "Solar assisted photocatalytic oxidation of distillery waste", Indian chemical Engr., vol. 40, No. 59, 1998.

[6]. Murugan malaiyandi, M.Husain Sadar, Pauline Lee \& Ron O'Grady, "Removal of Organics in Water Using Hydrogen Peroxide in Presence of Ultraviolet light" Water Research, Vol. 14, pp. 1131-1135, 1980.

[7]. Patienence C. Ho "Photoxidation of 2,4Dinitrotoluene in Aqueous solution in the presence of hydrogen peroxide" J. of Environ. Sci. Technol., Vol. 20, No.3, pp. 260-267, 1986.

[8]. D.W. Sundstrom, B.A. Weir, \& H.E.Klei, "Destruction of Aromatic Pollutants by UV light catalysed oxidation with hydrogen peroxide", J. Environmental Progress, Vol. 8, No.1, pp. 6-11, 1989.

[9]. William H. glaze \& Joon-Wun Kang, "Advanced Oxidation Process, Description of a kinetic model for the oxidation of hazardous materials in aqueous media with ozone and hydrogen peroxide in a semibatch reactor", Ind.Eng.Chem.Res., Vol. 28, pp 1573-1480, 1989.

[10]. Christoph K. Scheck \& Fritz H. Frimmel, "Degradation of Phenol and salicyclic acid by ultraviolet radiation/hydrogen peroxide/oxygen", Water Research, Vol. 29, No. 10, pp. 2346-2352, 1995.

[11]. 11. Ching- Rong Huang \& Hung- Yee Shu, " The reaction kinetics, Decomposition pathways and intermediate formation of phenol in ozonation, $\mathrm{UV} / \mathrm{O}_{3}$ and $\mathrm{UV} / \mathrm{H}_{2} \mathrm{O}_{2}$ processes, Journal of Hazardous Materials, Vol. 41, pp. 47-64, 1995.

[12]. 12. I.N. Martyanov, E.N. Saninov \& V.N. Parmon, "A comparative study of efficiency of photooxidation of organic contaminants in water solutions in various photochemical and photocatalytic systems 1. phenol photooxidation promoted by hydrogen peroxide in a flow reactor", J. of photochemistry and Photobiology, Vol. 107, pp. 227-231, 1997.

[13]. 13. Asim K.De, Sekhar Bhattacharjee \& Binay K. Dutta,"Kinetics of phenol Photooxidation by hydrogen peroxide and Ultraviolet Radiation", Ind. Eng. Chem. Res., Vol. 36, pp. 3607-3612, 1997.

[14]. 14. J.C. Crittenden, Shumin Hu, David W. Hand \& Sarah A. Green, " A kinetic model for $\mathrm{H}_{2} \mathrm{O}_{2} / \mathrm{UV}$ process in a completely mixed batch reactor", Pll: S0043-1354 (98)00448-5.

[15]. 15. Partha P. Mitra \& Tapan Kr. Pal, "Treatment of effluent containing phenol by catalytic conversion", Indian Chem. Engr. Section A, Vol. 41, No. 1, pp. T22T26,1999.

[16]. 16. Asim K.De, Sekhar Bhattacharjee, \& Binay K. Dutta, "Estimation of OH radicals reaction rate constants for phenol and chlorinated phenols using $\mathrm{UV} / \mathrm{H}_{2} \mathrm{O}_{2}$ photooxidation", J. of Hazardous Materials, Vol. B64, pp. 91-104, 1999.

[17]. 17. Asim K. De, Basab Chaudhuri Sekhar Bhattacharjee, \& Binay K. Dutta. "A practical Application of the advanced oxidation process for wastewater treatment", Indian Chem. Engr. Section A, Vol. 41, No. 2, pp. T63-T66, 1999.

[18]. 18. Aparana Rathi, M. Pandit \& R.K. Sharma, " Photo-oxidative degradation of direct yellow 12 using hydrogen peroxide", Indian J. of Chemical Technology, Vol. 6, pp. 297-300, 1999.

[19]. 19. H. Gallard \& J.De Laat, "Kinetic modeling of $\mathrm{Fe} \quad(111) / \mathrm{H}_{2} \mathrm{O}_{2}$ oxidation reactions in dilute aqueous solution using atrazine as a model organic compound", Water Research, Vol. 34, No. 12, pp. 31073116, 2000.

[20]. 20. James E. Duffy, Marc A. Anderson, Charles G. Hill, Jr. Walter A. Zeltner," Photocatalytic oxidation as a secondary 
treatment method following wet air oxidation", Ind. Engr. Chem. Res., Vol. 39, pp. 3698-3706, 2000

[21]. 21. Fares K. Neccheiwat \& Andy G. Swanson, "Clean contaminated sites using fenton's reagent", Chemical engineer progress, April 2000.

[22]. 22. Deepika Mogra, Mukesh Mehta, Ramesh Ameta \& Suresh C. Ameta, "Photochemical degradation of pdichlorobenzene by photo-fenton's reagent", J. Indian. Chem. Society, Vol. 79, pp. 593$595,2002$.
[23]. 23. S. Sabhi \& J. Kiwi, "Degradation of 2, 4-dichlorophenol by immobilized iron catalysts", Water Research, Vol. 35, No. 8, pp. 1994-2002, 2001.

[24]. 24. L. Yang, L.E. Yu, and M.B. Ray, "Photocatalytic oxidation of paracetamol in water", Vol. 142, pp. 578, 2007.

[25]. 25. Rajeev Jain and Meenakshi Srivastava "Photocatalytic removal of Hazardous dye cyanaosime form industrial waste using $\mathrm{TiO}_{2}$ ", Journal of Hazardous Materials, Vol. 152 , 216-220, 2008 